\title{
$\operatorname{arCOS} D E S I G N$
}

\section{Do Vinil ao Mp3: análise evolutiva das embalagens de discos no Brasil}

Ricardo Marques Sastre (UFRGS, Brasil)

ricsastre@gmail.com

Departamento de Expressão Gráfica

Universidade Federal do Rio Grande do Sul

Rua Sarmento Leite, 320 - Porto Alegre, RS

Marcelo Martel (Uniritter, Brasil)

marcelo_martel@uniritter.edu.br

Uniritter - Centro Universitário Ritter dos Reis

Av. Orfanotrófio, 555 - Porto Alegre, RS 


\title{
Do Vinil ao Mp3: análise evolutiva das embalagens de discos no Brasil
}

Resumo: O presente artigo tem por objetivo a descrição de um estudo sobre as capas de discos, que são as embalagens das plataformas de gravação, e suas relações com a evolução da música no Brasil. Para tanto, foram analisados aspectos históricos dos formatos em que eram registradas as músicas, os tipos de materiais utilizados na confecção das embalagens e os apontamentos sobre o design e os designers das capas de discos. Os resultados apontem que os materiais utilizados nas capas de discos foram adaptados aos novos formatos, tiveram suas matérias-primas modificadas e seus métodos de produção e design aperfeiçoado.

Palavras-chave: Design, Embalagem, Música Brasileira

\section{From Vinyl records to Mp3: An evolutionary analysis of disc packaging in Brazil}

\begin{abstract}
This paper aims to describe a study on the album covers, which are the packages of recording platforms, and its relations with the evolution of Brazilian music. There have been an analysis on: historical aspects of the formats in which the songs were recorded, the different types of materials used in the packaging manufacturing, the notes on the design and the designers of album covers. The results indicate that materials of Album Covers have adapted to new formats by modifying raw material and improving production, as well as, design methods.
\end{abstract}

Keywords: Design. Packaging. Brazilian music 


\section{Introdução}

A partir do surgimento do primeiro aparelho de reprodução musical, o fonógrafo, inventado por Thomas Alva Edison [1847-1931] em 1877, iniciou-se uma nova era de entretenimento no mundo. Três anos depois, em 1880, Alexander Graham Bell [1847-1922] apresentou um novo aparelho, introduzindo agulhas flutuantes no processo de gravação, que ficou conhecido como Gramophone.

Acompanhando essa evolução até os dias atuais, as embalagens que envolvem as plataformas de gravação também sofreram alterações ao longo do tempo, assim como o design evoluiu se apropriando dos espaços disponíveis nas capas para comunicação e divulgação dos artistas.

O presente artigo tem por objetivo a descrição de um estudo sobre as capas de discos, que são as embalagens das plataformas de gravação, e suas relações com a evolução da música no Brasil, desde a época das chapas duplas graváveis, passando pelos discos de vinil e compact disc, até as recentes gravações virtuais em extensão MP3. Para tanto, foram analisados aspectos históricos dos formatos em que eram registradas as músicas, os tipos de materiais utilizados na confecção das embalagens e os apontamentos sobre o design e os designers das capas de discos.

Este estudo é relevante na medida em que permite analisar se a evolução dos formatos das plataformas de gravação possui impacto na adaptação dos materiais e processos de produção empregados na confecção de suas embalagens, bem como na disposição dos espaços para a exploração do design contidos nas mesmas e no surgimento de profissionais especializados nesse segmento.

Os procedimentos metodológicos utilizados foram a pesquisa do tipo exploratória, para identificação e análise do design de algumas importantes capas de discos, e uma revisão de literatura que referencia e fornece subsídios a este estudo.

\section{História da música no Brasil}

Segundo Laus (2005), a música gravada teve inicio em 1892 através de Frederico Figner [1866-1947] no Rio de Janeiro, que comercializava aparelhos denominados "máquinas falantes“, cilindros e chapas gravadas. Esses cilindros cobertos com ceras podiam ser raspados e recobertos para posterior regravação. Conforme descrito nos anúncios da casa Edison, 
fundada pelo próprio em 1900, "na compra de um cilindro gravado, a entrega de um usado garantia um substancial desconto".

Em 1902 iniciaram-se as primeiras gravações comerciais no Brasil com duzentos e vinte e oito (228) músicas. O primeiro artista a gravar, segundo Severiano (1997), foi o baiano Manoel Pedro dos Santos [18701944], funcionário da casa Edison, uma canção denominada "Isto é bom", composta por Lundu de Xisto Bahia.

Uma importante novidade, entretanto, aconteceria na área tecnológica: o advento do disco brasileiro, em agosto de 1902. Entre os compositores do período, destacam-se três das maiores figuras da Música Popular Brasileira: Ernesto Nazareth, Chiquinha Gonzaga e Anacleto de Medeiros. (SEVERIANO. 1997, p.17)

Sem dúvida alguma, a possibilidade de gravar e reproduzir sons foi um grande acontecimento no Brasil, haja vista que a música está arraigada em nossa cultura desde o tempo do descobrimento e há registros de que os escravos já faziam cânticos e batucadas nas senzalas.

Em 1904, e com melhor precisão, em abril, a Sociedade Fonográfica Brasileira, instalada na rua dos Ourides, n 100 (hoje tem a denominação de Miguel Couto) anunciava em O Malho "a maior novidade do século XX". E como não achasse bem sensacional a epígrafe com duas exclamações dando-lhes ênfase, ajuntava mais. "o maior attractivo para as crianças". Frases apresentadas em caracteres bem legíveis e ilustradas com a fotografia de um gramofone da época (de campana afunilada e tendo ao lado a necessária chave de dar corda). Seu preço era também atraente. Cada Gramofone com seis discos custava apenas $20 \$ 000$ (Vinte mil réis ou vinte cruzeiros antigos. (EFEGÊ. 1978, p.190).

Em 1913 teve inicio a primeira fábrica de discos da América Latina: a Odeon. A empresa International Talking Machine, com sede em Berlim, tinha em sua origem capital majoritário Francês e acabou mantendo, como selo principal, a denominação Disques Odeon, uma homenagem ao famoso teatro parisiense. Segundo Laus (2005), em sociedade com Frederico Figner, no Rio de Janeiro, a fábrica Odeon, localizada no bairro de Vila 
Isabel, chegou a produzir um milhão e meio de discos por ano, tornando-se na época a quarta maior produtora de discos do mundo.

Em 1927, com a chegada das gravações elétricas - sistema de gravação eletromagnético mais sensível registrado pela Victor - abriu-se espaço a um sem número de cantores e cantoras de menor volume vocal. Segundo Laus (2005), foi considerado o período de ouro da Música Popular Brasileira, impulsionado também pelo surgimento da Rádio Nacional em 1936.

As eletrolas surgiram na década de cinquenta no Brasil e executavam discos de $78 \mathrm{rpm}$ (rotação por minuto) que reproduziam apenas cinco minutos de cada lado, ocasionando uma troca repetida e incômoda para quem os escutava. Os discos eram feitos de um composto de goma-laca e cera de carnaúba, também eram pesados, muito frágeis e cheios de ruídos e chiados.

Segundo Severiano (1997), em 1948 após muitos anos de pesquisa, surge no mercado um revolucionário formato de disco, denominado LongPlay e abreviado rapidamente para LP. Funcionava em rotação de 33 1/3 rpm e com o diâmetro de doze polegadas, os LPs eram prensados em um plástico denominado Cloreto Polivinílico popularmente conhecido como vinil. Segundo Laus (2005), das cinco companhias que produziam vinil em 1950, passaram a existir mais de vinte até meados da década de 1980, o que gerou empregos para mais de cem mil pessoas e tornando o vinil o segundo tipo de plástico mais vendido no mundo.

No início dos anos 60, o mundo começava a ser sacudido pelos movimentos contraculturais. O disco de vinil aposentava definitivamente os antigos e frágeis discos de goma-laca. Para nós, os discotecários, além de revolucionários, os discos de vinil eram material de trabalho. (PEREIRA, 2012).

Outra descoberta importante para o armazenamento de músicas foram as Fitas Cassete, lançada em 1963 pela Philips. O cassete era constituído por dois carretéis, uma fita magnética e um envoltório plástico desenvolvido para posicionar a passagem da fita pelo leitor (cabeçote) do rádio. Para que fosse possível escutar o álbum desde o inicio, era necessário rebobinar a fita magnética e colocá-la na posição de origem. Com um tamanho aproximado de 10x7 centímetros, a fita cassete economizava bastante espaço na prateleira. Mais adiante, surgiram aparelhos que faziam gravações de uma fita cassete para outra e ainda eletrodomésticos portáteis 
chamados de Walkman que, através de fones de ouvido, deram inicio a uma época de apreciação musical individual.

Em 1979, segundo Duarte (2007), a empresa Holandesa Philips, fez uma revolução no mercado: lançou o Compact Disc system, toca discos que utiliza um mini canhão de raio laser no lugar das tradicionais agulhas e trabalha com discos de apenas doze centímetros de diâmetro, cobertos por uma camada de plástico protetor que impede arranhões e riscos. Os discos laser, denominados "CD" têm capacidade de armazenar até setenta minutos de música, quase o dobro dos LPs.

$\mathrm{O}$ "CD" se tornou popular no Brasil na década de noventa e praticamente tomou conta do espaço musical pela sua praticidade, maior durabilidade e baixa suscetibilidade a arranhões. A produção de discos de vinil praticamente se extinguiu, mas atualmente algumas gravadoras estão relançando títulos consagrados como um símbolo "cult", porém com preço de aquisição muito elevado que na época.

Com a intenção de continuar reduzindo espaços e promover ainda maior praticidade, surge o MP3. Segundo Duarte (2007), o MP3 existe desde 1987 e foi invenção de um instituto de tecnologia Alemão, o Fraunhofer Institut Integriert Schaltungen. Seu nome é uma abreviação de MPEG áudio layer-3. Foi possível reduzir o tamanho do som de um "CD" comum, de forma que, sem perder qualidade, ele coubesse em um espaço ainda menor. $\mathrm{O}$ número três significa que houveram duas tentativas anteriores de comprimir o som, mas não tão eficientes quanto o MP3

CRONOLOGIA DE FATOS HISTÓRICOS NA VIDA DOS DISCOS de 1901 a 1957

\begin{tabular}{|c|l|}
\hline \multicolumn{2}{|c|}{ CRONOLOGIA DE FATOS HISTORICOS NA VIDA DOS DISCOS de 1901 a 1957} \\
\hline DATA & \multicolumn{1}{c|}{ ACONTECIMENTO } \\
\hline $02 / 08 / 02$ & A casa Edson lança o primeiro lote de discos gravados no Brasil \\
\hline $21 / 12 / 12$ & É prensado pela primeira vez um disco no Brasil; Início das atividades da fábrica ODEON \\
\hline $25 / 11 / 15$ & Pela primeira vez na história o disco ultrapassa um milhão de cópias vendidas (Carry me to Old Virginia, com Alma Gluck) \\
\hline $07 / 09 / 22$ & É realizada a primeira transmissão de rádio no Brasil \\
\hline $01 / 04 / 25$ & A Victor lança nos EUA os primeiros discos comerciais gravados pelo sistema elétrico \\
\hline $01 / 10 / 43$ & É fundada a gravadora de discos Continental \\
\hline $21 / 06 / 48$ & A Columbia Americana lança o LP de 33 rpm e a Philco lança o aparelho para a reprodução do disco \\
\hline $31 / 01 / 51$ & A Sinter lança o primeiro LP Brasileiro, com músicas de Carnaval \\
\hline & \\
\hline
\end{tabular}

Tabela 01. Cronologia de fatos históricos na vida dos discos de 1901 a 1957 (fonte: Severiano, 1997)

\section{Materiais utilizados nas embalagens de discos}

Nessa parte deste estudo é apresentada uma análise dos materiais utilizados nas capas de discos, suas características e processos de produção empregados na sua confecção. 


\section{1. Os primeiros discos}

Os primeiros materiais utilizados para o registro das músicas eram os cilindros, comercializados em embalagens também cilíndricas de papelão, que segundo Laus (2005), eram identificados apenas com a marca do fabricante. Com os primeiros discos acontecia a mesma coisa, porém estes permitiam a identificação do nome da loja em alguns casos.

Os primeiros discos eram protegidos em um envelope de papel Kraft de gramatura fina. Segundo Twede (2010), o Kraft é um papel marrom originário da Escandinávia e a palavra Kraft significa: "forte", o que possibilita sua utilização em embalagens. As capas de discos possuíam um buraco no meio para visualização das informações do rótulo colado no centro do disco, tais como: o nome do artista, a relação das músicas, a gravadora e a identificação do lado "A" ou "B". A impressão era feita em tipografia com poucas cores e o corte era feito com a ajuda de uma máquina de corte e vinco, utilizando uma matriz de corte e, após dobrado e colado em duas partes deixando, apenas um dos lados ficava aberto para possibilitar a colocação e retirada do disco.

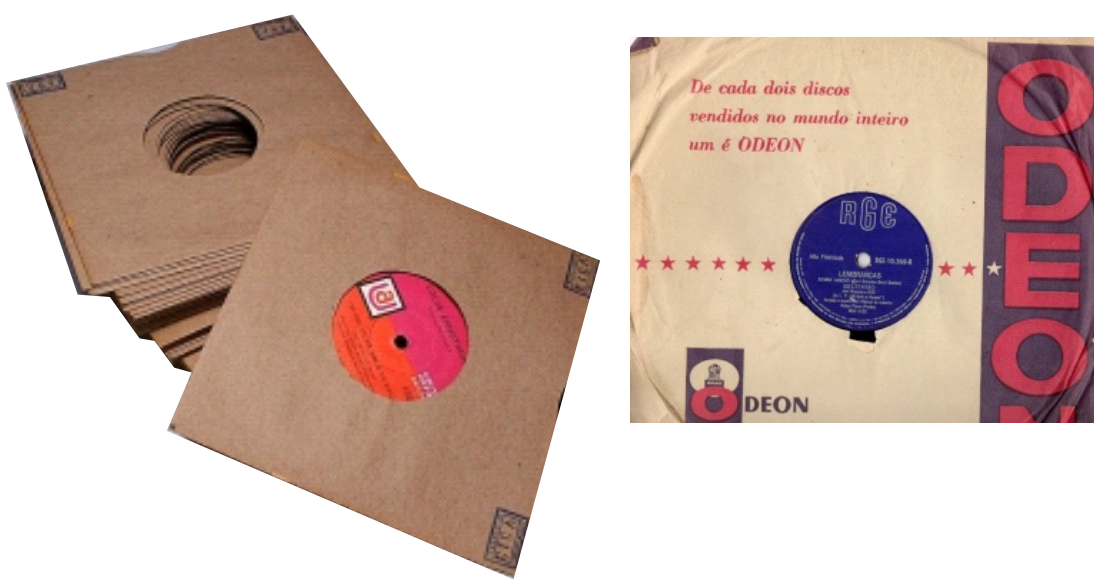

Figura 01. Primeiras capas de discos (fonte: arquivo pessoal do autor)

\section{2. Discos de vinil}

Os discos de vinil eram produzidos através da prensagem das informações das músicas nos dois lados em um formato com 12 polegadas de diâmetro. 
As capas inicialmente eram impressas em tipografia mas, devido à preocupação em desenhar embalagens mais atraentes e com espaços maiores, o processo de impressão foi modificado e migrou para o Off-set, o que possibilitou a reprodução de imagens coloridas.

O papel utilizado nas embalagens era o cartão duplex. Conforme Sandri (2009), o duplex é um papel produzido com múltiplas camadas e em gramaturas que variam de $180 \mathrm{gm}^{2}$ a $450 \mathrm{gm}^{2}$. O cartão é revestido com diversas camadas de tinta, o que proporciona uma superfície branca e lisa, adequada para receber uma boa impressão. O papel é composto de celulose branqueada, pasta mecânica e materiais reciclados.

O envelope dos discos era do tamanho 32 × $32 \mathrm{~cm}$, estampado em uma máquina de corte e vinco com o auxílio de uma matriz de corte, dobrado e colado em duas partes, deixando apenas uma abertura para a entrada e saída do disco, assim como nos modelos anteriores.

O disco era protegido por um envelope plástico e, em alguns casos, era encartada uma folha fina (de baixa gramatura), contendo a letra das músicas e até mesmo um pôster do artista.

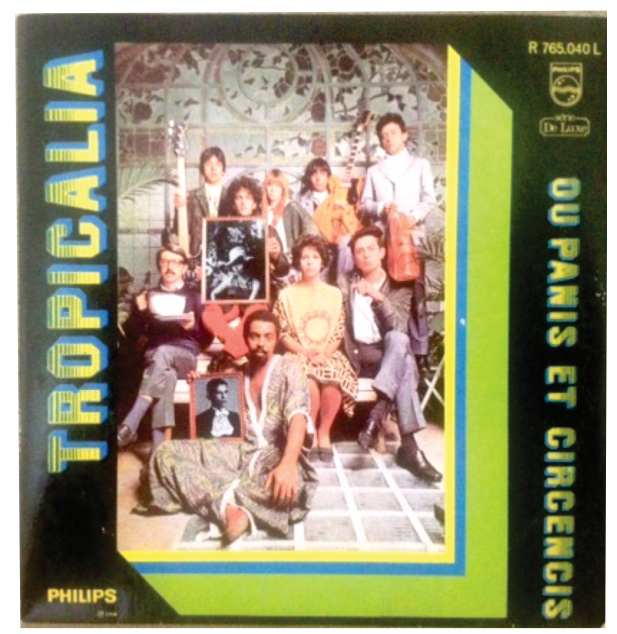

Figura 2. Embalagem utilizada para discos de vinil (fonte: arquivo pessoal do autor)

\section{3. Compact Disc “CD”}

As embalagens de Compact Disc em sua maioria são compostas por um plástico rígido transparente de $14 \mathrm{~cm}$ de comprimento por $12,5 \mathrm{~cm}$ de altura e $01 \mathrm{~cm}$ de largura, que comportam capa, contracapa e suporte para fixar o CD. 
Na parte interna da embalagem existe um encaixe para colocação de um encarte impresso, geralmente em papel couchê brilho $90 \mathrm{~g}$, colorido e reproduzido no processo de impressão off-set, com variação do número de folhas de acordo com a criação e ou os desejos do artista. Entre a parte traseira e o suporte do disco, há também uma encarte com folha simples para revestimento do verso e das laterais do álbum.

Também podem ser encontradas capas mais sofisticadas e mais largas, como nos casos de discos duplos ou estojos de coleções. Um exemplo bastante diferenciado é do álbum Pulse da banda britânica Pink Floyd, que utilizou em sua capa um dispositivo de LED (Light Emitting Diode) vermelho piscante, que funcionava através de pilhas acopladas internamente, que simbolizava a pulsação do corpo humano.

Atualmente, em virtude da grande disponibilidade de músicas em formato virtual, houve uma significativa redução das vendas de CDs e, também por este motivo, as gravadoras começaram a produzir um tipo de capa mais econômico, que é uma espécie de envelope de papel. Na parte interna à direita há um suporte para o disco em plástico e na parte interna esquerda há um encaixe em papel para colocação do encarte, geralmente contendo as letras das músicas, a ficha técnica do álbum, algumas imagens e outras informações importantes.

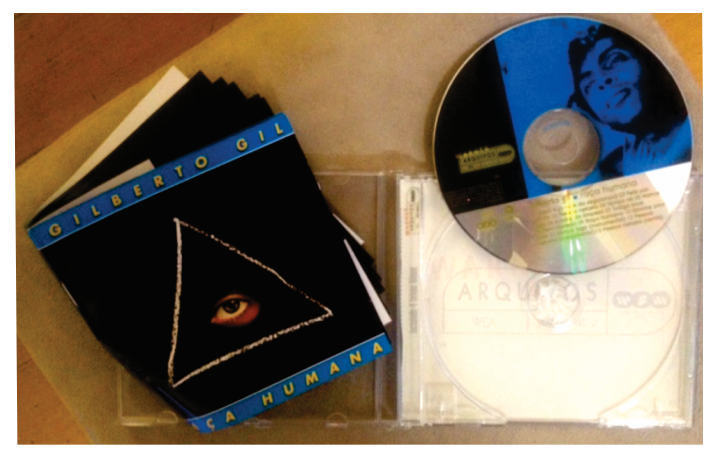

Figura 3. Componentes de um Compact Disc (fonte: arquivo pessoal do autor)

\subsection{Mp3 - Discos virtuais}

Com a possibilidade de redução do tamanho das músicas contidas em um "CD" convencional, o MP3 proporcionou o armazenamento e/ou execução de canções em diferentes dispositivos eletroeletrônicos tais como, telefones celulares, pen drives, tocadores específicos de MP3, memórias externas de computadores, dentre outros. 
Existem diversos programas que simulam uma discoteca no computador e que possibilitam, com o auxílio da internet, a aquisição das capas dos discos e das informações das músicas. É Possível também o aproveitamento de vários outros recursos como a criação de uma Playlist (lista de músicas), personalizada, a equalização das músicas e até mesmo a produção de efeitos utilizados por um “DJ” (Disc-Jockey)

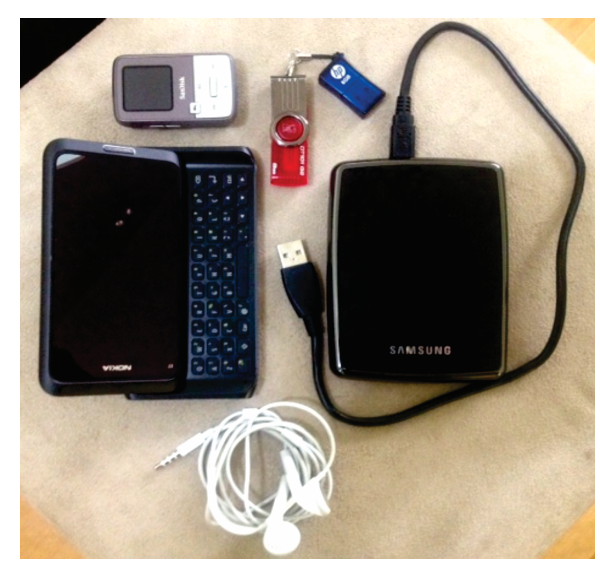

Figura 4. Aparelhos eletrônicos utilizados para reproduzir sons em Mp3 (fonte: arquivo pessoal do autor)

\section{Design das capas}

Conforme anteriormente mencionado, no Brasil as capas dos primeiros discos continham apenas o nome da gravadora e sua função era prioritariamente de proteção dos discos, sem uma preocupação explícita com o design.

Posteriormente as lojas começaram a produzir capas personalizadas com suas marcas. Segundo Laus (2005), os primeiros indícios de capas mais elaboradas no Brasil apontam para o final dos anos quarenta. Curiosamente, tratavam-se de discos direcionados para o público infantil, lançados pela gravadora Continental e possivelmente criados por Alceu Penna [19151980], um famoso estilista e desenhista.

De acordo com Laus (2005), em 1950 foi lançado um disco de Cantigas de Roda, com desenhos de Di Cavalcanti [1897-1976], também para a Continental, e nesse mesmo ano, o artista ilustrou um álbum de 78 rpm de Aracy de Almeida interpretando Noel Rosa. Após os anos cinquenta, 
a produção de capas de discos começou a tomar vulto e muitas capas começaram a ser ilustradas.

A Sociedade Interamericana de Representações (SINTER), fundada em 1945, montou a primeira fábrica de LPs no país e foi a primeira empresa a se preocupar com o design continuado das capas de discos.

Os profissionais responsáveis pela criação das capas de discos transitavam pelo mercado editorial, pelo teatro e pela televisão. Os designers gráficos eram um misto de ilustradores e paginadores, autodidatas e formados dentro de agências e/ou revistas.

Na história de todos os produtos, o design da embalagem sempre apresenta a perspectiva de novidade. A matériaprima evolui, melhora, passa por aprimoramentos, mas pela própria condição de palpável, concreta, não pode avançar além de seus limites físicos, intrínsecos. Quem lhe dá a forma é o design. Filho da imaginação, irmão da fantasia com foco na realidade dos negócios, ele não tem limites. Completado o prazo da inovação tecnológica, começa a hora do design, da beleza, do acabamento, das cores, do brilho. (CAVALCANTI, 2006, p. 171).

Existem muitos designers e estúdios especializados em capas de discos atualmente, mas alguns dos expoentes e precursores desse ofício foram Elifas Vicente Andreato, César Villela e Rogério Duarte, que são apresentados a seguir.

\subsection{Elifas Andreato}

Artista gráfico, cenógrafo e jornalista, nasceu em Rolândia no Paraná, em 1946. Iniciou sua carreira aos 14 anos de idade trabalhando como torneiro mecânico para a Fiat Lux. Aos 18 anos foi para a TV Record como assistente de cenografia. Contratado em 1967 como estagiário na Editora Abril, trabalhou nas revistas Cláudia, Manequim, Quatro Rodas e Realidade. Em 1970, participou da criação da revista Placar e da coleção História da Música Brasileira. 
Destacou-se como criador de capas de discos para os mais importantes nomes da Música Popular Brasileira. O trabalho de capista continuou durante a década de oitenta, com destaque para discos de Chico Buarque (Ópera do malandro, Almanaque e Vida), Vinicius de Moraes e Toquinho (Arca de Noé 1 e 2, Um pouco de ilusão), Toquinho (Aquarela e Casa de brinquedo), Clara Nunes, Paulinho da Viola (Zumbido, Amor e natureza, Nervos de aço, Cantando e chorando, Prisma luminoso, Eu canto samba e Bebadosamba), João Bosco (Essa é sua vida e Bandalhismo), Egberto Gismonti, Martinho da Vila, Zeca Pagodinho, dentre outros. Elifas recebeu 24 prêmios concedidos as suas capas de discos.

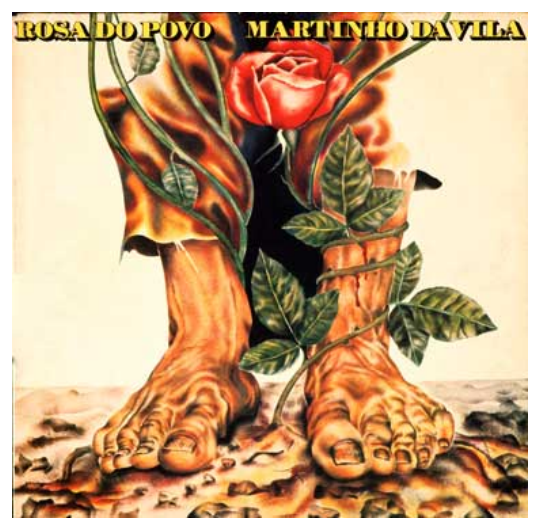

Figura 5. Capa assinada por Elifas Andreato (fonte:www.ibacbr.com.br)

\subsection{César Villela}

Segundo Laus (2005), César Villela é um dos mais influentes artistas gráficos brasileiros. Começou a invadir as embalagens dos discos no final dos anos cinquenta, quando fazia dezenas de capas por mês para a gravadora Odeon e encontrava tempo e inspiração suficiente para criar imagens lindas e elegantes, como a do disco “Ooooh, Norma”, de Norma Benguell, e vários de Silvinha Telles.

Em 1963 acompanhou o produtor Aloysio Oliveira quando esse saiu da Odeon e criou sua própria gravadora, a revolucionária Elenco, que lançou os discos de estreia de gente como Nara Leão, Tom Jobim, Vinicius de Moraes, Edu Lobo, Astrud Gilberto e álbuns de Baden Powel, Roberto Menescal e Maysa. Na Elenco, César Villela abusou do minimalismo e 
ajudou a criar a imagem da própria Bossa Nova: elegante, discreta, moderna e ousada.

Segundo Charles Gavin, em entrevista publicada em 2012 no site de noticias UOL as imagens criadas por César Villela para o selo Elenco marcaram uma estética nova no design gráfico brasileiro e se tornaram sinônimo da Bossa Nova e da elite intelectual carioca dos anos sessenta. O preto e o branco predominavam nas capas produzidas por Villela, que em sua maioria eram pontuadas apenas por pequenos detalhes em vermelho. Villela ajudou a Bossa Nova a conquistar o Brasil e o mundo.

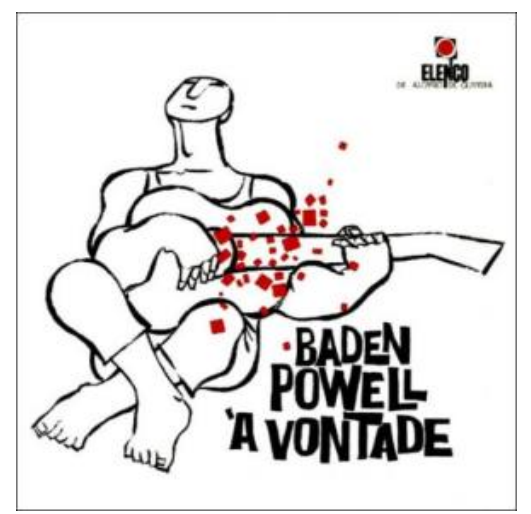

Figura 6. Capa assinada por Cesár Villela (fonte: www.ffw.com.br)

Segundo o próprio Cesar Villela, a capa era o principal veículo de venda, era ela quem deveria estimular, ou melhor, motivar a compra. Não havia outra ponte, era ela e o cliente. Suas capas brigavam com as de outras empresas nas vitrines das lojas. Havia um carnaval de cores e Villela sentiu a necessidade de mudar, simplificando o visual, para conferir mais destaque às mesmas.

\subsection{Rogério Duarte}

Artista gráfico, músico, compositor, poeta, tradutor de sânscrito e professor universitário, Rogério Duarte foi um dos mentores intelectuais do movimento Tropicalista e conviveu com personalidades como Caetano Veloso, Capinam, Gilberto Gil, Gláuber Rocha, Tom Zé e Wally Salomão.

Baiano de Ubaíra, nascido em abril de 1939, começou a atuar como designer gráfico nos anos sessenta. Desenvolveu cartazes, capas de discos e 
livros, identidades visuais, ilustrações e trabalhos de sinalização. Seu projeto de maior destaque foi o cartaz para o filme "Deus e o Diabo na Terra do Sol" de Glauber Rocha.

Seus projetos são marcados pela cultura e cores bem brasileiras, que podem ser vistas em capas de discos tropicalistas como os de Caetano Veloso e Gilberto Gil.

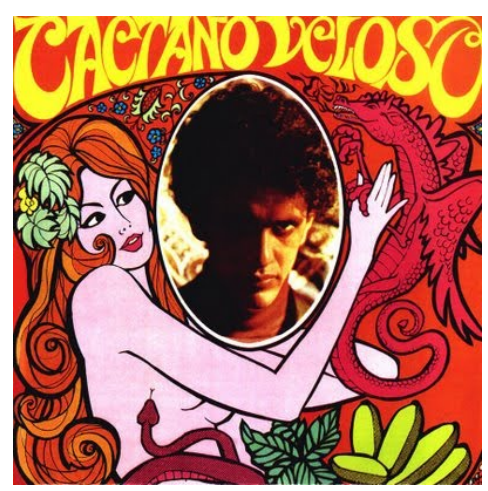

Figura 7. Capa assinada por Rogério Duarte (fonte: www.ifd.com.br)

\section{Considerações finais}

Desde as primeiras gravações comerciais no Brasil, a música impulsionou um grande mercado que envolveu lojas de equipamentos e discos, gravadoras e fábricas e popularizou a música brasileira, auxiliada pelo o surgimento da rádio Nacional em 1936. O mercado gráfico também foi beneficiado com a expansão desse novo segmento. A necessidade de divulgar o artista e comunicar-se no ponto de venda levou as gravadoras a se preocuparem com o design das capas dos discos.

Foi possível verificar através deste artigo que os formatos das plataformas de gravação tiveram influência na adaptação dos materiais utilizados na confecção das capas de discos, bem como em seus processos de produção (matérias-primas, impressão e acabamentos), tornando ao longo do tempo os discos mais atraentes e de melhor qualidade visual.

As capas dos LPs, os discos de vinil, foram as que mais propiciaram o trabalho dos designers. Havia espaço disponível para explorar melhor os aspectos visuais e consequentemente foi a época em que começou a surgir os profissionais especializados em desenhar capas de discos. 
O mercado fonográfico se tornou um segmento muito importante para a manifestação cultural do Brasil, tendo movimentado grandes indústrias e contribuído na formação de profissionais especializados. Os designers oriundos de diversas áreas da comunicação começaram a se especializar na criação das capas de discos e contribuíram de alguma forma na concepção da identidade visual de alguns segmentos importantes da música brasileira, como a Bossa Nova e o Tropicalismo. Além disso, estimularam a concorrência e o consumo de discos através de desenhos que chamassem atenção no ponto de venda.

O intérprete ou compositor quando produz um disco com diversas músicas ele esta se manifestando culturalmente, expressando todos os seus sentimentos e recebendo as influências do local aonde vive. Cabe ao designer ajudar a transmitir através da criação das capas de discos, todos os reflexos da expressão do artista, trabalhando juntos com o objetivo de transformar a obra em um sucesso de vendas e em um expoente para a história da Música Popular Brasileira.

Percebe-se que com a evolução dos formatos das plataformas de gravação houve uma perda no romantismo de ouvir uma música segurando a capa do disco e apreciando seus aspectos visuais. Poucas pessoas ainda preservam esse hábito. As capas atuais estão representadas de forma reduzida e virtual em uma tela de computador ou celular, deixando de ocupar espaços nas prateleiras das casas de seus consumidores. Como trabalhos futuros fica em aberto uma análise visual dos espaços virtuais disponíveis para a promoção e a distribuição da música no Brasil.

\section{Referências}

CAVALCANTI, Pedro. História da embalagem no Brasil. 1 Edição. São Paulo: Grifo Projetos Históricos e Editoriais, 2006. 255 p.

DUARTE, Marcelo. O guia dos curiosos: invenções. 1 edição. São Paulo: Panda Books, 2007. 464 p.

EFEGÊ, Jota. Figuras e coisas da música popular Brasileira. 1 Edição. Rio de Janeiro: FUNARTE, 1978. 262 p.

FFW, http://ffw.com.br/noticias/cultura-pop/mostra-reve-designbrasileiro-atraves-de-capas-de-discos-da-bossa-nova/. Acesso em $05 / 12 / 2012$ 
IBACBR, http://www.ibacbr.com.br/?dir=biografias\&verBio=00039. Acesso em $04 / 12 / 2012$

IFD, http://www.ifd.com.br/blog/design/rogerio-duarte-o-designertropicalista/. Acesso em 03/12/2012

LAUS, Egeu. Capas de discos: os primeiros anos. In: CARDOSO, Rafael (org). O design Brasileiro antes do design: aspectos da história gráfica 18701960. 1 Edição. São Paulo: Cosac Naify, 2005. 360 p.

PEREIRA, Claudinho. Na ponta da agulha: embalos na noite de Porto Alegre. 1 Edição. Porto Alegre: Editora da cidade, 2012. 204 p.

SANDRI, Fernando Wagner. Embalagens em papel cartão, papel e micro ondulado. 1 Edição. São Paulo: Instituto de embalagens, 2009. 176 p.

SEVERIANO, Jairo. A canção no tempo 85 anos de músicas Brasileiras. 1 Edição. São Paulo: Ed. 34, 1997. 368p.

TWEDE, Diana. Materiais para embalagens. 2 Edição. São Paulo: Blucher, 2010. 171 p.

UOL,

http://www.musica.uol.com.br/ultnot/2008/07/31/ult5955u28.jhtm. Acesso em 04/12/2012 